dogs. We should pay more attention to left-behind children in rural areas who parents working outside to big cities.

\section{ASSOCIATION BETWEEN TEMPERAMENT AND FRACTURE RISK IN PRESCHOOL-AGE CHILDREN: A CASE CONTROL STUDY}

${ }^{1}$ Kandace Ryckman, 1,2,3 Sarah A Richmond 11 Aura Anderson, ${ }^{1}$ Catherine Birken, ${ }^{1}$ Patricia Parkin, ${ }^{1}$ Colin Macarthur, ${ }^{4}$ Jonathon Maguire, ${ }^{1}$ Andrew Howard. ${ }^{1}$ Hospital for Sick Children, Canada; ${ }^{2}$ York University, Canada; ${ }^{3}$ University of Calgary, Canada; ${ }^{4}$ University of Toronto, Canada

\subsection{6/injuryprev-2016-042156.461}

Background Approximately half of all children will sustain a fracture during childhood and adolescence. Understanding the factors that place a child at increased risk of fracture is necessary to inform effective injury prevention strategies.

Methods A case-control study design with 128 cases and 426 frequency-matched controls (age and sex) was used to examine the risk of fracture (radiologist diagnosed fracture) in children ages 3-6 years. Cases were recruited from the Hospital for Sick Children Fracture Clinic and controls from the TARGet Kids primary care paediatric network. The Childhood Behaviour Questionnaire (CBQ), a 36-item caregiver response questionnaire was used to assess three temperament factors: surgency (i.e. impulsivity, high activity level); negative affect (i.e. anger, fear, discomfort); and effortful control (i.e. inhibitory control, attentional focusing) as the exposure.

Results Unadjusted logistic models demonstrated no association between children with a fracture and higher scores of surgency (unadjusted OR $=1.06,95 \% \mathrm{CI}: 0.84,1.34$ ), negative affect (unadjusted OR $=1.15,95 \%$ CI: $0.93,1.42$ ) or effortful control (unadjusted OR $=0.80,95 \% \mathrm{CI}: 0.63,1.03$ ). Models adjusted for covariates (waist circumference, maternal education, history of fracture, attendance in daycare, amount of time spent in unstructured playtime outdoors, having been breastfed, daily milk and soda consumption), also demonstrated no significant association with surgency $(\mathrm{OR}=1.00,95 \% \mathrm{CI}: 0.78,1.29)$, negative affect $(\mathrm{OR}=1.09,95 \% \mathrm{CI}: 0.86,1.37)$ and effortful control $(\mathrm{OR}=0.80,95 \% \mathrm{CI}: 0.61,1.05)$.

Conclusions Children who are more extraverted, impulsive, aggressive or easily distracted as measured by the CBQ, are not at greater odds of experiencing a fracture, compared to their peers.

\section{CO-DESIGN PROJECT TO RAISE AWARENESS AROUND SEXUAL VIOLENCE AND SAFETY IN AUCKLAND YOUTH}

Kristin Good. Accident Compensation Corporation and Auckland District Health Board, Auckland, New Zealand

\subsection{6/injuryprev-2016-042156.462}

Background New Zealand has one of the highest rates of child sexual violence in the developed world. One in four girls are sexually abused before the age of 15 . Maori and Pacific Island girls are at significantly increased risk compared to European girls. Most abuse occurs at home by someone that is known to them. One in seven boys may be sexually abused before adulthood. The average age of abuse is nine.

Long-term effects of sexual violence on children can be significant. Untreated, there is a strong correlation with mental health disorders and lifelong social problems. Cultural differences influence the way youth interpret and respond to sexual violence. Social and economic costs are high.

Methods Youth with lived experience were involved in co-designing a Youth Innovation Forum with the local District Health Board and Accident Compensation Corporation. Sexual violence was a focus of the day. Novel ways of communicating through youth were used, including music and theatre, to create a powerful message raising awareness. Social media was an important tool. Cultural aspects were important in designing the final product. Psychological support was available on the day to ensure safety.

Results The creative intervention was powerful. It became the focal point of the day. Following the presentation a number of youth came forward seeking help for themselves and others. Psychological support was essential to ensure safety. Feedback confirmed the value of the presentation in increasing awareness and understanding. Repeat performances and a video presentation have spread the message to wider audiences. The success of the day has ensured funding for the event next year.

Conclusions Co-design ensured the message was relevant to youth. Including youth in delivering the message increased the relevance to the audience. Social media was effective in supporting the campaign. Psychological support is essential when delivering a powerful message to a potentially vulnerable audience.

\section{A RESEARCH ON E-DEVICES AND WALKING AMONG TEENS IN SHANGHAI: HOW THEY DO AND WHAT THEY SAY}

${ }^{1}$ Fannie Wang, ${ }^{2}$ Yan $Y u,{ }^{1,3}$ Mulder Wang, ${ }^{1}$ Xinyi Hou, ${ }^{2}$ Monica Cui, ${ }^{4} J u a n j u a n$ Peng ${ }^{4}$ Wenjuan Jiang. 'Safe Kids China, Shanghai; ${ }^{2}$ Shanghai CDC, Shanghai; ${ }^{3}$ Shanghai Traffic Police, Shanghai; ${ }^{4}$ Shanghai Education Commission, Shanghai

\subsection{6/injuryprev-2016-042156.463}

Background Road traffic accidents is the first killer to teens aged 15-17 worldwide. In China, the same trend happens on teens. They are the group walking independently on the one hand, they are the group with the highest increasing rate on web-surfacing through mobile phone on the other hand. This research presented the results through observation, group discussion and questionnaire on teens distracted walking by e-devices in Shanghai, which is the first of its kind in China.

Methods 8250 observations of teens in 8 communities in fall 2014 and spring 2015 were recorded. Observers conducted two morning and afternoon sessions at cross roads, on different days but at the same time, on regular school days in good weather. Each observer focused on one crossing location. 8 focus group discussions were conducted among 176 teens and 1000 questionnaires were completed by teens in 8 communities.

Results $50 \%$ of teens reported use of e-devices while walking in the questionnaire. Reported by observers at cross roads, 240 out of 8250 teens were observed distraction by e-devices while crossing in a quick traffic flow with a car passing by every 2.7 seconds. The distraction rate in the afternoon is 1.9 times vs morning. The most frequent forms of distraction were headphones $42.5 \%$, texting $22.5 \%$, game $15.8 \%$, and talking on the phones $(10.4 \%)$. During focus groups, $86.6 \%$ of teens perceived either senior or junior groups at greater risk. Safety talks on walking with e-devices with parents is in need among teens.

Conclusions Teens represent a growing proportion of road traffic victims. Prevalance use of e-devices among teens proposed growing risk. Evidence-based intervention is strenuous in need. 